\title{
A new method for detecting deception in Event Related Potentials using individual-specific weight templates
}

\author{
Abdulmajeed Alsufyani ${ }^{1,2^{*}}$, Alexia Zoumpoulaki ${ }^{1}$, Marco Filetti ${ }^{1}$, Howard Bowman ${ }^{1}$ \\ From Twenty Second Annual Computational Neuroscience Meeting: CNS*2013 \\ Paris, France. 13-18 July 2013
}

A new method called the weight template (WT) is proposed for classifying Event related potentials (ERPs) into deceiving and non-deceiving. In this study, EEG data from two P300-based lie detection experiments were analyzed to demonstrate the efficiency of the WT method in detecting deception. A comparison was made with a common method used to measure P300 presence, called Peak-to-Peak, which is believed to be more accurate than other methods in measuring P300 amplitudes $[1,2]$. One experiment consisted of presenting participants with birth date stimuli and 12 participants were instructed to lie about their own birthday. The other experiment consisted of 15 participants who were instructed to lie about their first names [3]. Using simulated EEG data [4], Receiver Operating Characteristic (ROC) curves were also generated to examine the efficiency of the proposed method in detecting deception in low signal-to-noise ERPs.

Typically, P300-based lie detection systems employ the P300 component to detect concealed information. They present three stimulus types: Probes $(\mathbf{P})$, which represent concealed information or crime details and can be recognized only by the guilty person; Irrelevants (I), which are frequent and task (crime)-irrelevant, and Targets ( $\mathbf{T}$ ), which are irrelevant items, but participants are asked to do a task whenever they see a Target. For practical lie detection, the key comparison is between Probe and Irrelevant ERPs, since, for the nondeceiver, the former would be an Irrelevant. Importantly, the Probe for a deceiver typically generates a P300 ERP component, which is absent for the Irrelevant. The principle underlying the

\footnotetext{
* Correspondence: asa41@kent.ac.uk

${ }^{1}$ Centre for Cognitive Neuroscience and Cognitive Systems (CCNCS), School of Computing, University of Kent, Canterbury, Kent, CT2 7NF, UK Full list of author information is available at the end of the article
}

WT method is that as the Target stimulus is task-relevant, it will evoke a robust P300 pattern for each subject, which we hypothesize is characteristic in form and polarity of that individual's P300. Accordingly, this $T$ ERP can serve as an individual-specific template, with which to search for the Probe P300. Specifically, the difference between $\boldsymbol{T}$ and $\boldsymbol{I}$ ERPs was used as a template (i.e. effectively as a kernel) and this template was applied to $\boldsymbol{P}$ and $I$ ERPs.

Using such a template, with some pre-processing steps, we found that the WT achieved significantly better detection performance in comparison to Peak-to-Peak. In the names lie detection, the WT was able to detect deception for $93 \%$ in the guilty group compared with $80 \%$ by Peak-to peak. The false alarm rates using WT and Peak-to-Peak were $2 \%$ and $8 \%$ respectively. In the birthdays lie detection, hit rates were 50\% using WT and 33\% using Peak-to-Peak. The false alarm rates of both methods were $5 \%$. ROC curve analysis also showed that in ERPs with high signalto-noise ratio (SNR), both methods could detect deception successfully and almost equally. However, the WT performed better in ERPs with low SNR. We thus conclude that the WT is simple and very effective for detecting deception, even in ERPs with low SNR.

\section{Author details \\ ${ }^{1}$ Centre for Cognitive Neuroscience and Cognitive Systems (CCNCS), School of Computing, University of Kent, Canterbury, Kent, CT2 7NF, UK. \\ ${ }^{2}$ Department of computer science, Taif University, Taif, 21974, Saudi Arabia.}

Published: 8 July 2013

\section{References}

1. Hu X, Hegeman D, Landry E, Rosenfeld JP: Increasing the number of irrelevant stimuli increases ability to detect countermeasures to the P300-based Complex Trial Protocol for concealed information detection. Psychophysiology 2012, 49:85-95. 
2. Soskins M, Rosenfeld JP, Niendam T: Peak-to-peak measurement of P300 recorded at $0.3 \mathrm{~Hz}$ high pass filter settings in intraindividual diagnosis: complex vs. simple paradigms. International journal of psychophysiology : official journal of the International Organization of Psychophysiology 2001, 40:173-80.

3. Bowman H, Filetti M, Janssen D, Su L, Alsufyani A, Wyble B: Subliminal Salience Search Illustrated: EEG Identity and Deception Detection on the Fringe of Awareness. PLOS ONE 2013, 8:e54258.

4. Yeung N, Bogacz R, Holroyd CB, Cohen JD: Detection of synchronized oscillations in the electroencephalogram: An evaluation of methods. Psychophysiology 2004, 41:822-832.

doi:10.1186/1471-2202-14-S1-P34

Cite this article as: Alsufyani et al:: A new method for detecting

deception in Event Related Potentials using individual-specific weight templates. BMC Neuroscience 2013 14(Suppl 1):P34.

\section{Submit your next manuscript to BioMed Central} and take full advantage of:

- Convenient online submission

- Thorough peer review

- No space constraints or color figure charges

- Immediate publication on acceptance

- Inclusion in PubMed, CAS, Scopus and Google Scholar

- Research which is freely available for redistribution

Submit your manuscript at www.biomedcentral.com/submit
Ciomed Central 